\title{
ANATOMIA DA MADEIRA DE Mimosa cruenta Benth. (LEGUMINOSAE MIMOSOIDEAE)
}

José Newton Cardoso Marchiori

Departamento de Ciências Florestais. Centro de Ciências Rurais. UFSM. Santa Maria, RS.

RESUMO

São descritos os caracteres gerais, macroscópicos e micros cōpicos do xilema secundärio de Mimosa cruenta Benth., e fornecidos dados quantitativos, estereológicos e fotomicrografias da madeira.

A estrutura anatômica é analisada sob o ponto de vista ta xonōmico, sendo reconhecidos caracteres que permitem a inclusão da espēcie na Sērie Stipelzares Benth., do gēnero Mimosa L.

PALAVRAS CHAVE: Anatomia da Madeira, Mimosa cruenta Benth., Legumi nosae Mimosoideae.

\section{SUMMARY}

MARCHIORI, J.N.C., 1985. Wood Anatomy of Mimosa cruenta Benth., (Le guminosae Mimosoideae). Ciência e Natura, 7:73-81.

The general, macroscopic and microscopic anatomical cha racteristics of the secondary xylem of Mimosa cruenta Benth. are described. Quantitative and stereological data, as well as photomi crographs of the wood, are also furnished.

The anatomical structure is analysed based on Wood Taxonomy, characteristics that permit the inclusion of the species in the Stipezzares Benth. Series of the Mimosa L. genus being recognized. KEYWORDS: Wood Anatomy, Mimosa cruenta Benth., Leguminosae Mimoso $\underline{i}$ deae.

\section{INTRODUÇÃO}

0 gênero Mimosa L. compreende cerca de 400 espécies de er vas e arbustos, raras vezes ärvores, dispersas em sua maioria na Amé rica, desde 0 sul dos Estados Unidos atē a Argentina e Uruguai. Tra ta-se de um gênero megatērmico, com grande poliformismo no Mēxico, Brasil e Argentina (BURKART, 3).

O Brasil é particularmente rico em espēcie de Mimosa. A revisão de Bentham para a Flora Brasiliensis, trata de 199 espēcies, distribuĩdas em duas Secções e 21 Sēries. Em direção ao sul da Amé rica observa-se uma nītida redução em nūmero de espécies, havendo, segundo BURKART (5), 48 espēcies e 10 variedades no Estado de Santa Catarina, 42 no Rio Grande do Sul (RAMBO, 13) e apenas 20, de acor do com LOMBARDO (9), na Repūblica Oriental do Uruguai.

A maior parte das espécies de Mimosa são plantas de pequeno 
porte e de utilização desconhecida. Apenas Mimosa scabrezra Benth. e Mimosa bimucronata (DC.) 0. Ktze. são cultivadas para a produção local de madeira e lenha (BURKART, 4). A utilização limitada da ma deira não estimulou a realização de estudos anatômicos no gēnero, sendo poucas espécies para as quais foram descritos os caracteres gerais, macroscópicos e microscópicos da madeira.

0 presente trabalho trata da descrição da estrutura do xi lema secundārio de uma espécie nativa no sul do Brasil e visa con tribuir para o melhor conhecimento anatómico da madeira no gēnero Mimosa.

\section{REVISAOO DE LITERATURA}

Mimosa cruenta Benth. è arbusto inerme, de atē 1,5 m de altura, encontrado em āreas de campo no sul do Brasil, Mesopotāmia Argentina e Uruguai, preferencialmente em habitats secos e pedrego sos (RAMBO, 13). BURKART (5) fornece à espécie o nome popular de ju quiri.

De acordo com BENTHAl (2), Mimosa cruenta pertence à Secção Habbasia, por ter flores diplostêmones, e à série Stipezzares, devi do à presença de capitulos globosos axilares, legumes subplanos de valvas indivisas, e folhas 1-3-jugas, com estipelas orbiculares.

A Anatomia da Madeira em Mimosa foi muito pouco pesquisa da. Caracteres gerais e organolēpticos para as madeiras do gēnero, são citadas por RECORD \& HESS (14), com base na observação de ape nas 2 espēcies.

MARCHIORI (10) descreveu a anatomia da madeira e da casca de Mimosa bimucronata e Mimosa seabrezza, comparando a estrutura des tas madeiras com a de outras duas, do mesmo gênero. Foram encontra das diferenças anatōmicas marcantes e constatada a necessidade de estudos mais profundos, utilizando um maior nūmero de espēcies para se possibilitar o reconhecimento de caracteres de real valor toxonô mico.

Em estudo mais recente, MARCHIORI (11) descreveu a anato mia do xilema secundārio de Mimosa daleoides Benth., confirmando a 1 guns caracteres de valor taxonōmico para a secção Eumimosa.

cozzo (7) comparou a estrutura anatōmica de 11 espécies na tivas da Argentina, com vistas a identificação e taxonomia. Foi ob servada uma ampla variação anatōmica, o que levou o autor a conside rar o gênero Mimosa como estruturalmente heterogēneo. Para Mimosa cruenta foi referida a presença de anēis de crescimento escassamen te demarcados, tendência à porosidade dendrîtica, elementos vascula res de curso retilíneo ou levemente sinuoso, placas de perfuração simples em tabiques oblíquos, apêndices ausentes ou escassos e cur tos, e pontuações intervasculares pequenas e medianas, com aberturas 
não coalescentes. Foram também relacionados para a espécie, a ocor rência de raios baixos e năo exclusivamente uni-seriados, parénqui ma axial abundante, fibras libriformes muito curtas, e a presença de traqueóides vasculares e de espessamentos espiralados finos em elementos vasculares estreitos.

\section{MATERIAL E METODOS}

O material estudado é procedente do Estado do Rio Grande do sul e consiste de exsicatas botānicas e amostras de caule lenho so, que se encontram anexadas às coleções do Herbário e xiloteca do Departamento de Ciēncias Flroestais, da Universidade Federal de San ta Maria, com os seguintes registros:

- HDCF 711. Narchiori, 30/9/1982. São Sepé, vargem da BR 290.

- HDCF 776. Lins, D., 24/9/1982. Arroio dos Ratos, RS.

Das amostras de madeira foram preparados bloquinhos orien tados para a obtenção de cortes anatômicos nos planos transversal, longitudinal radial e longitudinal tangencial. Os cortes foram rea lizados em micrótomo de deslizamento, próprio para madeiras, com a espessura nominal de $20 \mu \mathrm{m}$. Usou-se coloração, com safranina e azul -de-astra, e montagem permanente com "Entellan".

Para a dissociação do tecido lenhoso procedeu-se à macera ção de finos palitos de madeira em solução de ácido nītrico 10\% e ácido crōmico $10 \%$, em partes iguais. A pasta de células lenhosas re sultante foi neutralizada em solução aquosa de bicarbonato de sōdio e colorida com safranina, tendo sido montadas 5 láminas permanentes de cada amostra.

Para a descrição anatōmica seguiram-se as recomendações da COPANT (6), tendo sido usadas as determinações estereológicas descri tas em IfJU (8). Os dados quantitativos são apresentados na Tabela 1. As fotomicrografias da Figura 1 foram tomadas em aparelho Carl Zeiss, do Departamento de Morfologia da UfSM.

\section{DESCRIÇAO DA MADEIRA}

Caracteres gerais e organolépticos

Alburno e cerne indistintos. Madeira de cor castanho-cla ro com matiz esbranquiçado, brilhante, de grã direita ou linheira, moderadamente dura, de textura fina, sem odor e gosto caracteristi $\cos$.

Descricão macroscópica

Poros: Invisíveis a olho nū em plano transversal, visíveis sob lente de $10 x$, muito pequenos, muito numerosos, em distribuição difusa, uniforme, sem conteūdos. Poros principalmente em agrupamentos 
TABELA 1. DADOS QUANTITATIVOS E DETERMINAÇOES ESTEREOLOGICAS DA ES TRUTURA ANATŌMICA DA MADEIRA.

\begin{tabular}{|c|c|c|c|c|}
\hline CARACTERISTICA ANATŌMICA & $\begin{array}{l}\text { VALOR } \\
\text { MINIMO }\end{array}$ & MEDIA & $\begin{array}{l}\text { VALOR } \\
\text { MAXIMO }\end{array}$ & $\begin{array}{l}\text { DESVIO } \\
\text { PADRAOO }\end{array}$ \\
\hline 1. Fração dos poros (\%) & 6,0 & 10,0 & 15,0 & 2,86 \\
\hline 2. Comprimento elementos vasculares ( $\mu \mathrm{m})$ & 160,0 & 233,7 & 315,0 & 34,78 \\
\hline 3. Comprimento de apêndices ( $\mu \mathrm{m})$ & 10,0 & 43,3 & 80,0 & 24,60 \\
\hline 4. $\emptyset$ tangencial de poros $(\mu \mathrm{m})$ & 28,8 & 45,5 & 77,5 & 9,98 \\
\hline 5. Espessura parede de poros $(\mu \mathrm{m})$ & 1,3 & 1,7 & 2,5 & 0,46 \\
\hline 6. $\emptyset$ pontuações intervasculares $(\mu \mathrm{m})$ & 6,0 & 6,5 & 7,0 & 0,42 \\
\hline 7. $\emptyset$ pontuações rādio-vasculares $(\mu \mathrm{m})$ & 3,5 & 4,8 & 5,5 & 0,67 \\
\hline 8. $\emptyset$ pontuações parênquimo-vasculares $(\mu \mathrm{m})$ & 4,0 & 4,8 & 6,0 & 0,50 \\
\hline 9. Fração parênquima axial (\%) & 15,0 & 19,9 & 26,0 & 3,24 \\
\hline 10. H. cēlulas fusiformes $(\mu \mathrm{m})$ & 150,0 & 241,6 & 305,0 & 32,27 \\
\hline 11. L. cēlulas fusiformes $(\mu \mathrm{m})$ & 11,3 & 15,8 & 21,3 & 2,32 \\
\hline 12. H. cēlulas retangulares de sēries $(\mu \mathrm{m})$ & 67,5 & & 192 & 19,95 \\
\hline 13. L. cēlulas retangulares de sēries $(\mu \mathrm{m})$ & 8,8 & 14,5 & 22,5 & 3,02 \\
\hline 14. H. sēries parēnquima axial ( $\mu \mathrm{m})$ & 222,5 & 268,5 & 360,0 & 27,23 \\
\hline 15. Nọ células parênquimáticas/série & 2,0 & 2,1 & 3,0 & 0,14 \\
\hline 16. Fração tecido radial (\%) & 6,0 & 8,9 & 10,0 & 1,19 \\
\hline 17. Frequência de raios (raios/mm) & 5,0 & 7,7 & 11,0 & 1,37 \\
\hline 18. Fração raios uni-seriados (\%) & 60,0 & 66,2 & 71,0 & 3,52 \\
\hline 19. H. raios uni-seriados $(\mu \mathrm{m})$ & 50,0 & 153,7 & 282,5 & 56,58 \\
\hline 20. H. raios uni-seriados (células) & 1,0 & 6,6 & 14,0 & 3,06 \\
\hline 21. L. raios uni-seriados $(\mu \mathrm{m})$ & 8,7 & 15,8 & 28,8 & 3,61 \\
\hline 22. Fração raios bi-seriados (\%) & 29,0 & 33,8 & 40,0 & 3,52 \\
\hline 23. H. raios bi-seriados $(\mu \mathrm{m})$ & 112,5 & 210,7 & 402,5 & 60,87 \\
\hline 24. H. raios bi-seriados (células) & 5,0 & 10,9 & 21,0 & 3,19 \\
\hline 25. L. raios bi-seriados $(\mu \mathrm{m})$ & 12,5 & 23,3 & 36,3 & 5,07 \\
\hline 26. Fração de fibras (\%) & 58,0 & 61,2 & 67,0 & 2,65 \\
\hline 27. Comprimento de fibras $(\mu \mathrm{m})$ & 440,0 & 580,0 & 780,0 & 81,13 \\
\hline 28. $\emptyset$ total de fibras $(\mu \mathrm{m})$. & 7,5 & 11,4 & 15,0 & 1,80 \\
\hline 29. $\emptyset$ do lümem de fibras $(\mu \mathrm{m})$ & 2,5 & 6,0 & 10,0 & 1,98 \\
\hline 30.0 Espessura parede de fibras $(\mu \mathrm{m})$ & 1,9 & 2,6 & 4,4 & 0,53 \\
\hline
\end{tabular}

racemiformes com tendéncia a arranjo dendritico no plano transver sal; poros solitārios, geminados e em pequenos mültiplos, são menos típicos. Linhas vasculares retilineas, sem conteúdos.

Parênquima axial: Visível a olho nū ou com lente de lox, abundante, em disposição paratraqueal confluente, e formando manchas diagonais de padrão dendritico, de cor mais clara que o tecido fibroso. 

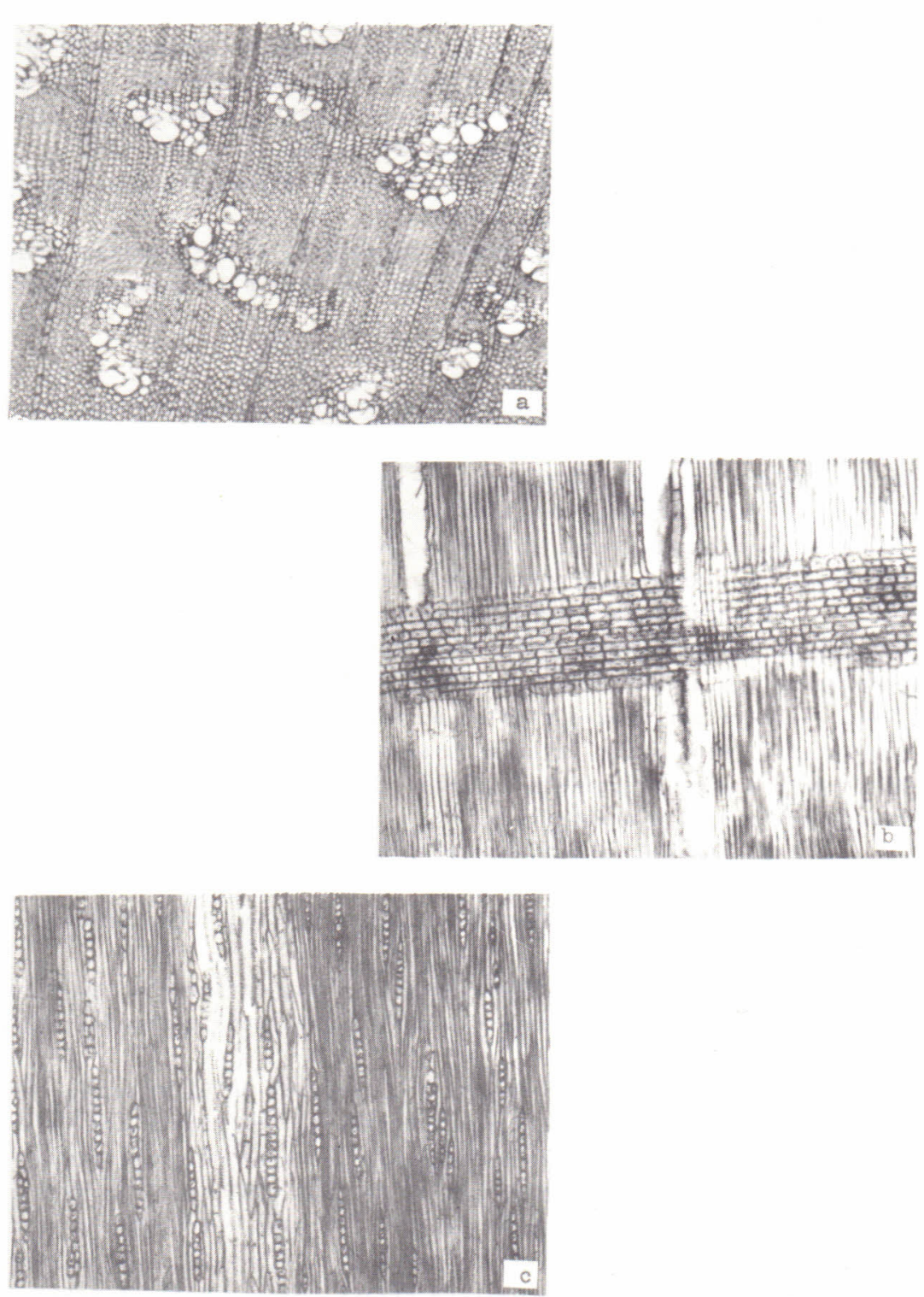

Figura 1. Fotomicrografias do lenho de Mimosa cruenta Benth.

a) Poros dispostos em agrupamentos ondeados e em cacho. Pla no transversal, $56 x$.

b) Tecido radial fracamente heterogêneo, visto em plano longitudinal radial $(56 \mathrm{X})$.

c) Corte longitudinal tangencial (56 X), mostrando raios ex clusivamente uni-seriados e agrupamentos longitudinais de poros: 
Raios: Invisíveis a olho nū em plano transversal, visíveis sem dificuldade sob lente.de $10 \mathrm{x}$, finos, pouco frequentes. Em pla no longitudinal tangencial, invisíveis a olho nū, visíveis sem di ficuldade sob lente, baixos, não estratificados. Espelhado dos raios pouco contrastado em plano longitudinal radial.

Anéis de crescimento: Distintos, individualizados por zo nas fibrosas tangenciais mais escuras.

outros caracteres: Canais secretores axiais, canais secre tores radiais, máculas medulares, líber incluso e listrado de estra tificação, ausentes.

Descricão macroscópica

Vasos: Extremamente numerosos, muito pequenos $(28,8-45,5$ - 77,5 $\mu \mathrm{m})$ e ocupando $10 \%$ da secção transversal da madeira. Poros de secção oval quando solitários, de parede celular fina $(1,3-1,7$ - 2,5 $\mu \mathrm{m})$, sem conteūdo, e dispostos principalmente em agrupamentos ondeados e em cacho. Poros solitários ou em outros padrões de agru pamentos, são menos característicos e conspícuos.

Elementos vasculares muito curtos (160 - 233,7 - 315 $\mu \mathrm{m})$, dotados de espessamentos espiralados ténues na parede celular, e geralmente com apēndices curtos $(10-43,3-80 \mu m)$, em uma extremi dade. Placa de perfuração simples e freqdentemente oblīqua em rela ção ao vaso. Pontuações intervasculares pequenas $(6,0-6,5-7,0 \mu \mathrm{m})$, de forma oval, em disposição alterna; com abertura lenticular, in clusa, horizontal e ornamentada.

Pontuações rādio-vasculares pequenas $(3,5-4,8-5,5 \mu \mathrm{m})$ e arredondadas, semelhantes às intervasculares. Pontuações parênqui mo-vasculares tambēm pequenas $(4,0-4,8-6,0 \mu \mathrm{m})$, semelhantes às rādio-vasculares.

Traqueóides vasculares encontram-se, em pequena quantida de, associados com os elementos vasculares, especialmente nos agru pamentos ondeados maiores.

Parênquima axial: Abundante, ocupando 19,9\% da secção trans versal da madeira; em disposição paratraqueal confluente até faixas curtas, em posições diagonal e tangencial ao anel de crescimento. Cé lulas fusiformes de parênquima axial, de $150-241-305 \mu m$ de altu ra por 11,3 - 15,8 - 21,3 um de largura. Cêlulas retangulares de 67,5 - 132,8 - 192,5 um de altura por 8,8 - 14,5 - 22,5 um de 1argu ra, são também frequentes, compondo sēries parenquimáticas axiais de 2 ou 3 células, com comprimento total de $222,5-268,5-360 \mu \mathrm{m}$.

Raios: Pouco numerosos (5 - 7,7 - $11 \mathrm{raios} / \mathrm{mm})$ e ocupando menos de $9 \%$ da secção transversal da madeira. Tecido radial fraca mente heterogêneo, composto de células horizontais, com fileira mar ginal de células quadradas e curtamente eretas. Raios em sua maioria 
uni-seriados $(66,2 \%)$, menos frequentemente bi-seriados $(33,8 \%)$.

Raios uni-seriados, extremamente baixos (50-153,7-282,5 $\mu \mathrm{m})$, muito finos $(8,7-15,8-23,8 \mu \mathrm{m})$ e com 1 - 6 - 14 células de altura. Raios bi-seriados, de região bi-seriada curta, extremamente baixos $(112,5-210,7-402,5 \mu \mathrm{m})$, de muito finos a finos $(12,5$ -

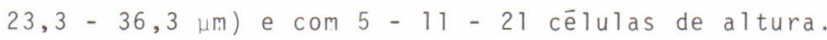

Células cristalíferas, envolventes, esclerosadas, lateri culiformes, oleíferas e mucilaginosas, ausentes em raios.

Fibras: Tecido fibroso proeminente, representando $61,2 \%$ do volume na madeira. Fibras de natureza libriforme, não septadas, frequentemente gelatinosas, dotadas de pontuações simples e diminu tas; extremamente curtas $(440-580-730 \mu \mathrm{m})$, estreitas $(7,5-11,4$ - $15 \mu \mathrm{m})$ e de paredes delgadas $(2,5-6,0-10,0 \mu \mathrm{m})$.

Outros caracteres: Canais secretores, tubos lacticiferos e taniniferos, líber incluso, máculas medulares e estratificação, ausentes. Goma e resina, não observados. Anēis de crescimento dis tintos, marcados pela presença de fibras de diâmetro radial menor e mais lignificadas no tērmino do anel. Cristais rombóides de oxalato de cālcio são pouco frequentes na madeira, ocorrendo em séries axiais de cámaras, dispersas no tecido fibroso.

DISCUSSÃO

Os caracteres anatōmicos mais conspicuos da estrutura do xilema secundärio de Mimosa cruenta Benth., tais como elementos vas culares com placa de perfuração simples, pontuações intervasculares ornamentadas e alternas, elementos vasculares muito curtos, e fibras com pontuações simples e muito pequenas são, de acordo com METCALFE \& CHALK (12), caracteres de ocorrência generalizada em Leguminosae. A ausência de estratificação completa de todos os elementos celula res e a predominância de células procumberantes e muito pequenas em raios, são caracteres considerados por BARETTA KUIPPERS (1) como in dicativos da sub-família Mimosoideae.

BARETTA KUIPPERS (1) observou pouca concordāncia na estru tura da madeira nas tribos de Mimosoideae, fato que atribui à fraca consistência na delimitação dos gêneros. A descrição anatômica de Mimosa, realizada por cozzo (7.) com base na análise de 11 espécies argentinas, mostra uma grande heterogeneidade estrutural na madeira. Os estudos de MARCHIORI $(10,11)$ tambēm ressaltam a grande variabi lidade anatômica existente no gênero.

Apesar da ausência de um "traço comum de união", referida por cozzo (7) para a anatomia da madeira em Mimosa, os táxones de natureza inferior parecem apresentar uma estrutura muito mais homo gênea.

E interessante se observar que na anälise de $\operatorname{cozzo}(7)$, 
Mimosa cruenta Benth., Mimosa uruguensis Hook. \& Arn., Mimosa Hassle riana Chod. e Mimosa Uliginosa Chod. \& Hassl. apresentam porosidade tendente a dendrítica e traquéoides vasculares associadas aos poros, distinguindo-se claramente das demais espécies por estes aspectos. As 4 espēcies citadas são pertencentes à Sērie stipezzares de Ben tham, a qual parece ser bastante natural pela anatomia da madeira.

Para a identificação da espēcie merecem destaque, a pre sença de espessamentos espiralados tênues em elementos de vaso dis sociados, a fraca heterogeneidade dos raios e dados quantitativos de diferentes tipos celulares da madeira.

CONCLUSOES

A anālise da estrutura anatômica permite a formulação das seguintes conclusões:

Os caracteres anatômicos mais importantes de Mimosa cruen ta Benth. são comuns em madeiras de Leguminosae e indicativos da sub-família llimosoideae.

A ocorréncia de porosidade tendente a dendritica e de tra queōides vasculares associadas aos poros permitem a inclusão da es pēcie na Sērie stipezzares de Bentham.

A existēncia de espessamentos espiralados tēnues em ele mentos vasculares, predomināncia de raios uni-seriados e a fraca heterogeneidade do tecido radial, são caracteres importantes para a identificação anatômica da espécie.

\section{LITERATURA CITADA}

1. BARETTA-KUIPPERS, T. Wood anatomy of Leguminosae - its relevance to Taxonomy. In: POLHILL, R.M. \& RAVEN, P.H. Advances in Le gume Systematics. Kew, Procc. of the International Legume Con ference, 1978. V. II: 677-705.

2. BENTHAM, G. Leguminosae III. Mimoseae. In: MARTIUS, C.F.P. de. Flora Brasiliensis. 1876. 15(2): 259-527.

3. BURKART, A. Las leguminosas argentinas silvestres y cultivadas. Buenos Aires, ACME Agency, 1952. 569 p.

4. BURKART, A. Leguminosae. In: PARODI, L.R. Enciclopedia Argentina de Agricultura y Jardineria. Buenos Aires, ACME S.A.C.I., 1959. v $1:$, 443-512.

5. BURKART, A. Leguminosas Mimosoideas. Flora Ilustrada Catarinense, 1979. 299 P.

6. COMISSAO PANAMERICANA DE NORMAS TECNICAS. Descrição macroscópica, microscópica e geral da madeira - esquema I de recomendação. Colómbia, 1973. 19 p. (COPANT 30).

7. Cozzo, D. Anatomia del leño secundario de las Leguminosas Mimo soideas y Caesalpinoideas argentinas silvestres y cultivadas. 
Rev. Inst. Nac. Invest. C. Naturates C. Bot., 2(2): 63-290, 1951 .

8. IFJU, G. Quantitative wood anatomy - a stereological approach. Blacksburg, VPI/IPT, 1977. $26 \mathrm{p}$.

9. LOMBARDO, A. Flora arborea y arborescente del Uruguay. Montevi deo, Concejo Departamental, s/d. $151 \mathrm{p}$.

10. MARCHIORI, J.N.C. Estudo anatômico do xilema secundário e da casca de algumas espécies dos gêneros Acacia e Mimosa, nati vas no Estado do Rio Grande do Sul. Curitiba, UFPr, 1980. 186f. Tese de Mestrado.

11. MARCHIORI, J.N.C. A estrutura do xilema secundārio de Mimosa da leoides Benth. (Leguminosae Mimosoideae). Ciêneia e Natura (4): $107-113,1982$.

12. METCALFE, C.R. \& CHALK, L. Anatomy of the Dicotyledons. Oxford, Clarendon Press, 1972. 1500 p.

13. RAMBO, B. Leguminosae Riograndenses. São Leopoldo, Instituto An chietano de Pesquisas. Bol. nọ 23, 1966. 166 p.

14. RECORD, S.J. \& HESS, R.W. Timbers of the New World. New Haven, Yale University Press, 1949. 640 p.

Recebido em outubro, 1985; aceito em novembro, 1985. 
